Article

\title{
Essential Oil Extraction, Chemical Analysis and Anti-Candida Activity of Calamintha nepeta (L.) Savi subsp. glandulosa (Req.) Ball-New Approaches
}

\author{
Mijat Božović ${ }^{1,2, \dagger}$, Stefania Garzoli ${ }^{2, \dagger}$, Manuela Sabatino ${ }^{1,2}$, Federico Pepi ${ }^{2}$, \\ Anna Baldisserotto ${ }^{3}$, Elisa Andreotti ${ }^{4}$, Carlo Romagnoli ${ }^{4}$, Antonello Mai ${ }^{2}$, \\ Stefano Manfredini ${ }^{3, *}$ and Rino Ragno ${ }^{1,2,5, *}$ \\ 1 Rome Center for Molecular Design, Sapienza University, P.le Aldo Moro 5, 00185 Rome, Italy; \\ mijat.bozovic@uniroma1.it (M.B.); manuela.sabatino@uniroma1.it (M.S.) \\ 2 Department of Drug Chemistry and Technology, Sapienza University, P.le Aldo Moro 5, 00185 Rome, Italy; \\ stefania.garzoli@uniroma1.it (S.G.); federico.pepi@uniroma1.it (F.P.); antonello.mai@uniroma1.it (A.M.) \\ 3 Department of Life Sciences and Biotechnology, School of Pharmacy and Heath Products, \\ University of Ferrara, Via L. Borsari 46, 44121 Ferrara, Italy; anna.baldisserotto@unife.it \\ 4 Department of Life Sciences, University of Modena and Reggio Emilia, Viale Caduti in Guerra 127, \\ 41121 Modena, Italy; elisa.andreotti@unimo.it (E.A.); carlo.romagnoli@unimo.it (C.R.) \\ 5 Alchemical Dynamics s.r.l., 00125 Rome, Italy \\ * Correspondence: stefano.manfredini@unife.it (S.M.); rino.ragno@uniroma1.it (R.R.); \\ Tel.: +39-532-974-635 (S.M.); +39-6-4991-3937 (R.R.); Fax: +39-532-455-953 (S.M.); +39-6-4991-3627 (R.R.) \\ + M.B. and S.G. contributed equally to the paper. \\ Academic Editor: Olga Tzakou \\ Received: 28 November 2016; Accepted: 24 January 2017; Published: 26 January 2017
}

\begin{abstract}
A comprehensive study on essential oils extracted from different Calamintha nepeta (L.) Savi subsp. glandulosa (Req.) Ball samples from Tarquinia (Italy) is reported. In this study, the 24-h steam distillation procedure for essential oil preparation, in terms of different harvesting and extraction times, was applied. The Gas chromatography-mass spectrometry (GC/MS) analysis showed that C. nepeta (L.) Savi subsp. glandulosa (Req.) Ball essential oils from Tarquinia belong to the pulegone-rich chemotype. The analysis of 44 samples revealed that along with pulegone, some other chemicals may participate in exerting the related antifungal activity. The results indicated that for higher activity, the essential oils should be produced with at least a 6-h steam distillation process. Even though it is not so dependent on the period of harvesting, it could be recommended not to harvest the plant in the fruiting stage, since no significant antifungal effect was shown. The maximum essential oil yield was obtained in August, with the highest pulegone percentage. To obtain the oil with a higher content of menthone, September and October should be considered as the optimal periods. Regarding the extraction duration, vegetative stage material gives the oil in the first $3 \mathrm{~h}$, while material from the reproductive phase should be extracted at least at 6 or even $12 \mathrm{~h}$.
\end{abstract}

Keywords: Calamintha nepeta (L.) Savi subsp. glandulosa (Req.) Ball; 24-h steam distillation; GC/MS; essential oils; anti-Candida activity; pulegone; menthone

\section{Introduction}

Plant essential oils (EOs) are usually complex mixtures of natural compounds, both polar and nonpolar [1]. They are principally composed of terpenoids and their oxygenated derivatives. Possessing antioxidant and antimicrobial activities, EOs serve as natural additives in foods and food products [2]. Known for their antiseptic (i.e., bactericidal, virucidal and fungicidal), 
medicinal properties and their fragrance, they are used in embalmment, preservation of foods and as antimicrobial, analgesic, sedative, anti-inflammatory, spasmolytic and local anesthetic remedies [3].

Indeed, many EOs and their ingredients have been proven to exhibit a wide range of biological activities that is even difficult to comprehensively report. In particular, antimicrobial properties of EOs are subject of continuous investigation both in vitro [4,5] and in vivo [6,7] against a wide range of pathogenic bacteria and fungi.

According to literature, EOs are mainly obtained by hydro- or steam distillation apparatus for 2-4 h (optionally 5). On the other hand, most of the data are related to some specific period of harvesting, e.g., flowering or fruiting periods. A comprehensive study on the EO, considering both extraction time and period of harvesting, from wild Mentha suaveolens Ehrh. (MS) has been reported recently [8]. Analogously, as in the MS study, we report herein a detailed study on C. nepeta (L.) Savi subsp. glandulosa (Req.) Ball (CG) EOs from Tarquinia (TEOCG), its chemical composition and the related antifungal activity.

\section{Taxonomic Characterization and Uses of C. nepeta (L.) Savi and Its Subspecies}

The genus Calamintha Miller includes aromatic plants belonging to the Lamiaceae family, well represented and widespread all around the Mediterranean region. These are medium to large size erect herbaceous perennials, sometimes woody at the base, represented by five polymorphic species in the European flora [9]. C. nepeta (L.) Savi (CN) is a bushy, rhizomatous herb similar to the common mint in its morphology and characteristic fragrance [10]. It includes two subspecies: nepeta (CNN) and glandulosa (CG), with the main differences in the number of flowers in cymes and leaf shape and size.

The subspecies CG, which was the subject of this investigation, grows up to $80 \mathrm{~cm}$. It is sparsely to densely pubescent, with leaves broadly ovate, obtuse, subentire or shallowly to deeply crenate-serrate with up to five teeth on each side [9] that are very fragrant when crushed. It typically forms a dense foliage usually found on rocky sites, dry meadows and abandoned places. Tiny, tubular, two-lipped, lilac to white flowers appear in axillary spikes (cymes 5- to 15-flowered) (Figure 1). It usually grows in summer (June/July), blooms during late summer followed by fruiting in autumn. Then it becomes dormant in the winter months, and re-blossoms in summer.

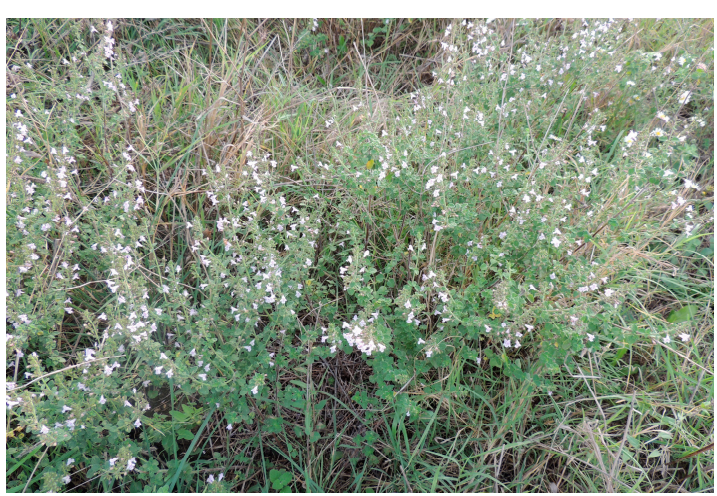

(a)

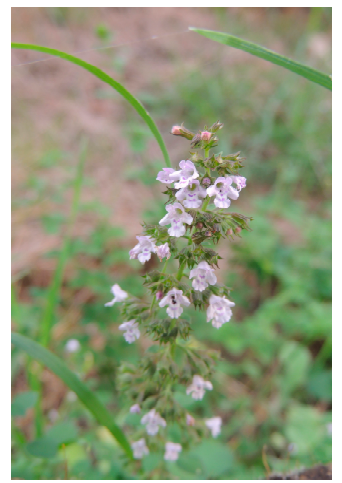

(b)

Figure 1. (a) C. nepeta (L.) Savi subsp. glandulosa (Req.) Ball (CG) in its natural habitat in Tarquinia countryside; (b) CG, close-up (photo: Mijat Božović).

A careful literature survey showed plenty of data, but most of them are related to CNN, or the material was not described in terms of subspecies (determined as $\mathrm{CN}$ ). The latter occurrence makes it particularly difficult to compare the existing data and to draw conclusions, taking into account the possibility of incomplete or even incorrect determination of material. Lastly, it can be said that these two subspecies share most of the uses and applications, since they are utilized in traditional medicine in different countries. Thus, $\mathrm{CN}$ is well-known for its medicinal uses as a stimulant, tonic, antiseptic and antispasmodic [11-14]. The chemical composition of its EO (TEOCG) has been 
thoroughly investigated [11-13,15-18], as well as its antioxidant $[19,20]$, antimicrobial $[14,21-23]$ and anti-inflammatory activities [14]. In the traditional medicine of different countries in the world, $\mathrm{CN}$ has also been widely used against insomnia, depression, convulsion and cramps [24] and for the treatment of respiratory and gastro-enteric diseases [14]. In several parts of Sicily, it is used for the disinfection and healing of wounds [21]. Its use against gout, expectorant and an external application of the leaves against hip pains, has been reported [14,25]. It is also used as a spice in Italian cuisine where it is called mentuccia or nipitella.

Several studies on TEOCG chemical composition were reported revealing different chemotypes in which the major components generally belong to the C-3 oxygenated $p$-menthanes [19] and can be grouped into three types of oils. The first and most popular chemotype is characterized by pulegone (PUL) as a major component, associated with menthone (MEN). It has been found wild in Italy [21,26], France [11], Turkey [12-14], Croatia [27] and Montenegro [22]. The second type is still characterized by PUL as a major component but associated with piperitenone. This chemotype has been reported in the material from Turkey [28], Greece [29] and Montenegro [22]. The third one can be considered as a piperitone oxide type, specific for the CG growing in Greece [30], or the piperitone oxide/piperitenone oxide one that has been noticed for the material from Turkey $[13,31]$ and Belgium [32]. A piperitone/piperitenone variant of this type was only reported for some Croatian material [19].

\section{Results and Discussion}

\subsection{EO Extraction}

Fresh aerial parts of CG were subjected to steam distillation and the oil was collected at various times (1, 2, 3, 6, 12 and $24 \mathrm{~h})$ during four successive months (see Material and Methods Section). The EO yield varied in function of both the harvesting period and the extraction intervals. The results showed different amounts of each fraction, but usually the main part of EOs was obtained in the first three (July harvest/August harvest) or six hours (September harvest/October harvest).

In the July harvest, the EO was almost completely extracted in the first two hours. Higher amounts of EO were extracted in the August harvest, likely due to higher temperature and other environmental conditions. Blooming material from the September harvest was characterized by high EO yield, not only in the first three fractions, but also between the third and sixth hours of extraction. The last one, October harvest material, was mainly in the fruiting phase and was characterized by the lowest yields (Figure 2a, Table 1).

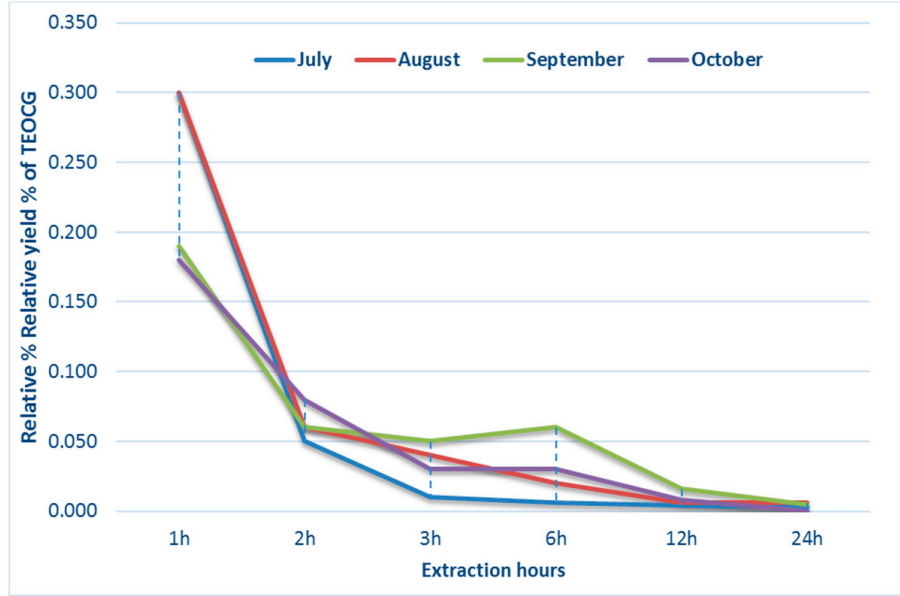

(a)<smiles>CC(C)=C1CC[C@@H](C)CC1=O</smiles><smiles>CCCCCC(C)C</smiles>

MEN

(b)

Figure 2. (a) Yield curves for CG; (b) chemical structures of pulegone (PUL) and menthone (MEN). 
Table 1. Relative yield \% of TEOCG over time.

\begin{tabular}{ccccc}
\hline $\mathbf{h}^{\mathbf{1}}$ & July $^{\mathbf{2}}$ & August & September & October \\
\hline 1 & 0.300 & 0.300 & 0.190 & 0.180 \\
2 & 0.350 & 0.360 & 0.250 & 0.260 \\
3 & 0.360 & 0.400 & 0.300 & 0.290 \\
6 & 0.366 & 0.420 & 0.360 & 0.320 \\
12 & 0.370 & 0.426 & 0.376 & 0.328 \\
24 & 0.373 & 0.432 & 0.381 & 0.328 \\
\hline
\end{tabular}

${ }^{1}$ extraction hour; ${ }^{2}$ harvesting month.

\subsection{GC/MS Analysis}

The GC/MS analysis of the 44 TEOCG samples highlighted the presence of 39 different chemical constituents, having different concentrations in the various fractions (Tables 2-5 and S1-S4 of Supplementary Materials). In general, PUL (36) was the most abundant component. Based on the extraction time in the July and August harvest, PUL percentage reached the maximum during the first three hours (J2h, A2h) whereas it diminished during the last three extractions. In the reproductive period of September and October, PUL percentage reached the maximum between the third and sixth (S6h) or twelfth hours (O12h). In all cases, PUL never disappeared and was present in smaller amounts in the last three fractions. It was particularly abundant in the August (84.7\%) and July harvest $(77.7 \%)$ samples. These findings are in compliance with previous reports [11-14,17,21,22,26,28,29,31-34]. PUL is a monoterpene ketone (Figure $2 b$ ) with a fresh odor reminiscent of mint, found in many Lamiaceae species. It was first isolated from the EO of Mentha pulegium L. from which its name was derived. This colorless liquid is very low soluble in water (less than $1 \%$ ), but miscible with organic solvents such as ethanol, diethyl ether and chloroform. Biochemically, PUL is derived from terpinolene through piperitenone, and it is also the precursor of MEN, isomenthone and isopulegone [35] and is usually encountered in combination with one or more of the mentioned compounds [36].

Table 2. Chemical composition (\%) of TEOCG extracted in July.

\begin{tabular}{|c|c|c|c|c|c|c|c|}
\hline$\#^{1}$ & Name & \multicolumn{6}{|c|}{ Sample $^{2}$} \\
\hline 4 & 3-octanol & $2.2 \pm 0.14$ & $0.4 \pm 0.03$ & $0.3 \pm 0.02$ & $0.4 \pm 0.03$ & $0.5 \pm 0.03$ & - \\
\hline 15 & cinerolone & - & - & - & $2.9 \pm 0.21$ & $5.8 \pm 0.42$ & - \\
\hline 17 & crysanthenone & $4.4 \pm 0.41$ & $10.5 \pm 0.98$ & $20.3 \pm 1.89$ & $22.7 \pm 2.11$ & $33.9 \pm 3.15$ & $27.3 \pm 2.54$ \\
\hline 18 & $\delta$-cadinene & - & - & - & $0.6 \pm 0.04$ & $0.8 \pm 0.05$ & $2.4 \pm 0.16$ \\
\hline 21 & isocaryophyllene & $0.3 \pm 0.02$ & - & $1.3 \pm 0.11$ & $2.9 \pm 0.24$ & $2.3 \pm 0.19$ & $3.8 \pm 0.36$ \\
\hline 22 & isopiperitenone & - & - & - & - & - & $2.2 \pm 0.19$ \\
\hline 23 & isopulegone & $0.6 \pm 0.05$ & $0.5 \pm 0.05$ & $0.5 \pm 0.05$ & $0.5 \pm 0.05$ & $0.4 \pm 0.04$ & - \\
\hline 24 & linalool & $0.3 \pm 0.02$ & - & $0.2 \pm 0.01$ & $0.4 \pm 0.02$ & $0.5 \pm 0.03$ & - \\
\hline 26 & menthone & $3.1 \pm 0.25$ & $0.8 \pm 0.06$ & $0.6 \pm 0.05$ & $0.6 \pm 0.05$ & $0.5 \pm 0.04$ & - \\
\hline 34 & $p$-menthene & - & - & - & $0.2 \pm 0.02$ & - & - \\
\hline 36 & pulegone & $76.8 \pm 5.91$ & $77.7 \pm 5.98$ & $64.3 \pm 4.95$ & $53.2 \pm 4.09$ & $41.1 \pm 3.16$ & $37.7 \pm 2.90$ \\
\hline 37 & sabinene & $0.6 \pm 0.05$ & - & - & - & - & - \\
\hline 38 & $\alpha$-terpineol & $0.3 \pm 0.02$ & $0.5 \pm 0.03$ & $0.7 \pm 0.04$ & $0.8 \pm 0.05$ & $1.2 \pm 0.07$ & - \\
\hline \multirow[t]{2}{*}{39} & trans- $p$-mentha-2,8-dienol & - & - & - & $0.2 \pm 0.02$ & $0.1 \pm 0.01$ & - \\
\hline & Unidentified compounds & $4.5 \pm 0.25$ & $7.9 \pm 0.44$ & $9.0 \pm 0.50$ & $9.5 \pm 0.53$ & $8.1 \pm 0.45$ & $11.8 \pm 0.66$ \\
\hline
\end{tabular}

${ }^{1}$ \# indicate the compound identification number; ${ }^{2}$ Samples' names were obtained by merging the first letter of the month and the extraction time as reported in Table 1. All compounds are not listed in order of elution. 
Table 3. Chemical composition (\%) of TEOCG extracted in August.

\begin{tabular}{rccccccc}
\hline \multirow{2}{*}{$\mathbf{H}^{\mathbf{N}}$} & Name & \multicolumn{7}{c}{ Sample $^{\mathbf{2}}$} \\
\cline { 3 - 7 } & & $\mathbf{A 1 h}$ & $\mathbf{A 2 h}$ & $\mathbf{A 3 h}$ & $\mathbf{A 6 h}$ & $\mathbf{A 1 2 h}$ & $\mathbf{A 2 4 h}$ \\
\hline $\mathbf{4}$ & 3-octanol & $1.6 \pm 0.15$ & $0.4 \pm 0.04$ & $0.2 \pm 0.02$ & $0.3 \pm 0.03$ & $0.5 \pm 0.05$ & $0.5 \pm 0.05$ \\
$\mathbf{5}$ & terpinen-4-ol & $0.4 \pm 0.04$ & $0.4 \pm 0.04$ & $0.5 \pm 0.05$ & $0.5 \pm 0.05$ & $0.7 \pm 0.06$ & $0.6 \pm 0.05$ \\
$\mathbf{7}$ & -cymene & $0.5 \pm 0.05$ & $0.4 \pm 0.03$ & $0.3 \pm 0.03$ & $0.5 \pm 0.05$ & $0.3 \pm 0.03$ & - \\
$\mathbf{9}$ & $\beta$-myrcene & $0.5 \pm 0.03$ & - & - & - & - & - \\
$\mathbf{1 2}$ & $\beta$-terpinene & $0.8 \pm 0.05$ & $0.1 \pm 0.01$ & - & - & - & - \\
$\mathbf{1 4}$ & caryophyllene oxide & - & - & - & $1.2 \pm 0.09$ & $1.8 \pm 0.13$ & - \\
$\mathbf{1 7}$ & crysanthenone & $2.6 \pm 0.25$ & $5.2 \pm 0.49$ & $9.0 \pm 0.86$ & $18.4 \pm 1.77$ & $24.0 \pm 2.30$ & $29.5 \pm 2.83$ \\
$\mathbf{1 8}$ & -cadinene & - & - & - & - & $0.5 \pm 0.04$ & $1.1 \pm 0.08$ \\
$\mathbf{1 9}$ & limonene & $7.5 \pm 0.46$ & $1.0 \pm 0.06$ & $0.6 \pm 0.04$ & $0.6 \pm 0.04$ & $0.2 \pm 0.01$ & - \\
$\mathbf{2 1}$ & isocaryophyllene & - & - & - & - & $1.3 \pm 0.09$ & $2.4 \pm 0.17$ \\
$\mathbf{2 3}$ & isopulegone & $0.6 \pm 0.05$ & $0.6 \pm 0.05$ & $0.6 \pm 0.05$ & $0.6 \pm 0.05$ & $0.8 \pm 0.06$ & $0.7 \pm 0.05$ \\
$\mathbf{2 4}$ & linalool & $0.4 \pm 0.03$ & $0.2 \pm 0.01$ & - & $0.2 \pm 0.01$ & $0.4 \pm 0.03$ & $0.3 \pm 0.02$ \\
$\mathbf{2 5}$ & menthol & $0.4 \pm 0.03$ & $0.5 \pm 0.03$ & $0.5 \pm 0.03$ & $0.5 \pm 0.03$ & $0.4 \pm 0.03$ & $0.4 \pm 0.03$ \\
$\mathbf{2 6}$ & menthone & $3.9 \pm 0.37$ & $2.1 \pm 0.19$ & $1.0 \pm 0.09$ & $0.8 \pm 0.08$ & $0.7 \pm 0.07$ & $0.7 \pm 0.07$ \\
$\mathbf{3 0}$ & piperitenone & - & - & - & $0.5 \pm 0.03$ & $0.8 \pm 0.04$ & $0.9 \pm 0.05$ \\
$\mathbf{3 3}$ & $p$-menth-1,8-dien-3-one & - & - & $0.4 \pm 0.03$ & $0.6 \pm 0.04$ & $1.0 \pm 0.06$ & $1.9 \pm 0.12$ \\
$\mathbf{3 2}$ & $p$-menth-1-en-8-ol & - & $0.5 \pm 0.03$ & $0.6 \pm 0.04$ & $1.0 \pm 0.07$ & $1.6 \pm 0.11$ & $2.7 \pm 0.19$ \\
$\mathbf{3 6}$ & pulegone & $80.8 \pm 5.49$ & $84.7 \pm 5.76$ & $80.0 \pm 5.44$ & $66.0 \pm 4.49$ & $55.4 \pm 3.77$ & $49.9 \pm 3.39$ \\
& Unidentified compounds & 0.0 & $3.9 \pm 0.22$ & $6.3 \pm 0.36$ & $8.3 \pm 0.47$ & $9.6 \pm 0.55$ & $8.4 \pm 0.48$ \\
\hline
\end{tabular}

${ }^{1}$ \# indicate the compound identification number; ${ }^{2}$ Samples' names were obtained by merging the first letter of the month and the extraction time as reported in Table 1. All compounds are not listed in order of elution.

Table 4. Chemical composition (\%) of TEOCG extracted in September.

\begin{tabular}{|c|c|c|c|c|c|c|c|}
\hline \multirow{2}{*}{$\#^{1}$} & \multirow{2}{*}{ Name } & \multicolumn{6}{|c|}{ Sample $^{2}$} \\
\hline & & S1h & S2h & S3h & S6h & S12h & S24h \\
\hline 2 & 2-hydroxypiperitenone & - & - & - & - & - & $1.1 \pm 0.09$ \\
\hline 4 & 3-octanol & $3.0 \pm 0.21$ & $1.7 \pm 0.12$ & $0.8 \pm 0.05$ & - & - & - \\
\hline 5 & terpinen-4-ol & $0.7 \pm 0.06$ & $0.6 \pm 0.05$ & $0.7 \pm 0.06$ & $0.6 \pm 0.05$ & $0.9 \pm 0.07$ & $0.7 \pm 0.06$ \\
\hline 7 & $p$-cymene & $0.8 \pm 0.08$ & - & - & - & - & - \\
\hline 9 & $\beta$-myrcene & $0.6 \pm 0.06$ & - & - & - & - & - \\
\hline 11 & $\beta$-pinene & $1.2 \pm 0.08$ & - & - & - & - & - \\
\hline 14 & caryophyllene oxide & $0.3 \pm 0.02$ & $0.5 \pm 0.03$ & $0.6 \pm 0.03$ & $0.7 \pm 0.04$ & $1.6 \pm 0.08$ & $1.8 \pm 0.09$ \\
\hline 15 & cinerolone & - & - & - & - & - & $2.9 \pm 0.5$ \\
\hline 17 & crysanthenone & $1.3 \pm 0.08$ & $2.0 \pm 0.13$ & $3.4 \pm 0.21$ & $6.8 \pm 0.43$ & $13.6 \pm 0.86$ & $18.6 \pm 1.17$ \\
\hline 18 & $\delta$-cadinene & - & - & - & - & - & $1.1 \pm 0.08$ \\
\hline 19 & limonene & $13.6 \pm 1.33$ & $2.1 \pm 0.20$ & $1.2 \pm 0.12$ & $0.6 \pm 0.06$ & $0.7 \pm 0.07$ & $0.7 \pm 0.07$ \\
\hline 23 & isopulegone & $1.1 \pm 0.07$ & $1.5 \pm 0.09$ & $1.3 \pm 0.08$ & $1.1 \pm 0.07$ & $1.1 \pm 0.07$ & $9.4 \pm 0.58$ \\
\hline 25 & menthol & $1.3 \pm 0.12$ & $2.2 \pm 0.20$ & $1.9 \pm 0.18$ & $1.9 \pm 0.18$ & $1.7 \pm 0.16$ & $1.7 \pm 0.16$ \\
\hline 26 & menthone & $20.3 \pm 1.52$ & $20.0 \pm 1.50$ & $11.2 \pm 0.84$ & $5.9 \pm 0.44$ & $4.1 \pm 0.31$ & $3.7 \pm 0.28$ \\
\hline 29 & $p$-cymen-8-ol & - & - & - & - & $0.7 \pm 0.06$ & $1.5 \pm 0.14$ \\
\hline 30 & piperitenone & $0.7 \pm 0.06$ & $1.5 \pm 0.13$ & $2.0 \pm 0.17$ & $3.1 \pm 0.26$ & $4.5 \pm 0.38$ & $3.9 \pm 0.33$ \\
\hline 31 & piperitenone oxide & $1.3 \pm 0.09$ & $1.3 \pm 0.09$ & $0.8 \pm 0.05$ & $0.5 \pm 0.03$ & - & - \\
\hline 33 & $p$-menth-1,8-dien-3-one & - & - & - & - & $0.9 \pm 0.07$ & $1.3 \pm 0.09$ \\
\hline 32 & $p$-menth-1-en-8-ol & $0.2 \pm 0.02$ & $0.4 \pm 0.03$ & $0.5 \pm 0.04$ & $0.6 \pm 0.05$ & $1.1 \pm 0.09$ & $1.6 \pm 0.14$ \\
\hline 36 & pulegone & $48.8 \pm 4.39$ & $62.5 \pm 5.62$ & $72.9 \pm 6.56$ & $74.9 \pm 6.74$ & $64.8 \pm 5.83$ & $43.2 \pm 3.89$ \\
\hline \multirow[t]{2}{*}{37} & sabinene & $1.4 \pm 0.14$ & - & - & - & - & - \\
\hline & Unidentified compounds & $3.4 \pm 0.20$ & $3.7 \pm 0.22$ & $2.7 \pm 0.16$ & $3.3 \pm 0.19$ & $4.3 \pm 0.25$ & $6.8 \pm 0.40$ \\
\hline
\end{tabular}

${ }^{1}$ \# indicate the compound identification number; ${ }^{2}$ Samples' names were obtained by merging the first letter of the month and the extraction time as reported in Table 1. All compounds are not listed in order of elution.

Table 5. Chemical composition (\%) of TEOCG extracted in October.

\begin{tabular}{|c|c|c|c|c|c|c|c|}
\hline$\#^{1}$ & Name & \multicolumn{6}{|c|}{ Sample $^{2}$} \\
\hline 3 & 3-metilcicloesanone & - & - & - & - & $0.9 \pm 0.06$ & $1.9 \pm 0.13$ \\
\hline 5 & terpinen-4-ol & $0.6 \pm 0.03$ & $0.7 \pm 0.03$ & $0.9 \pm 0.04$ & $0.9 \pm 0.04$ & $1.1 \pm 0.05$ & $0.8 \pm 0.04$ \\
\hline 14 & caryophyllene oxide & - & - & $1.0 \pm 0.06$ & $1.2 \pm 0.07$ & $1.8 \pm 0.11$ & $1.7 \pm 0.11$ \\
\hline 17 & crysanthenone & $1.3 \pm 0.11$ & $2.3 \pm 0.19$ & $3.3 \pm 0.28$ & $5.3 \pm 0.44$ & $5.4 \pm 0.45$ & $13.4 \pm 1.12$ \\
\hline 21 & iso-caryophyllene & $0.4 \pm 0.02$ & $0.6 \pm 0.04$ & $0.5 \pm 0.03$ & $0.7 \pm 0.04$ & $2.0 \pm 0.12$ & $3.5 \pm 0.21$ \\
\hline
\end{tabular}


Table 5. Cont.

\begin{tabular}{cccccccc}
\hline \multirow{2}{*}{$\boldsymbol{\#}^{\mathbf{1}}$} & \multirow{2}{*}{ Name } & \multicolumn{6}{c}{ Sample $^{\mathbf{2}}$} \\
\cline { 3 - 8 } & & $\mathbf{O 1 h}$ & $\mathbf{O 2 h}$ & O3h & O6h & O12h & O24h \\
\hline $\mathbf{2 3}$ & isopulegone & $1.0 \pm 0.05$ & $1.0 \pm 0.05$ & $1.2 \pm 0.06$ & $1.1 \pm 0.06$ & $1.3 \pm 0.07$ & $1.0 \pm 0.05$ \\
$\mathbf{2 5}$ & menthol & $4.3 \pm 0.25$ & $4.4 \pm 0.25$ & $6.3 \pm 0.36$ & $5.5 \pm 0.32$ & $5.3 \pm 0.31$ & $4.2 \pm 0.24$ \\
$\mathbf{2 6}$ & menthone & $35.4 \pm 3.01$ & $27.8 \pm 2.36$ & $23.6 \pm 2.01$ & $10.9 \pm 0.93$ & $7.0 \pm 0.59$ & $6.8 \pm 0.58$ \\
$\mathbf{3 1}$ & piperitenone oxide & $1.4 \pm 0.14$ & $1.9 \pm 0.18$ & $3.3 \pm 0.32$ & $3.6 \pm 0.35$ & $0.5 \pm 0.05$ & $5.2 \pm 0.51$ \\
$\mathbf{3 2}$ & p-menth-1-en-8-ol & $0.3 \pm 0.02$ & $0.3 \pm 0.02$ & $0.5 \pm 0.03$ & $0.8 \pm 0.05$ & $1.4 \pm 0.09$ & $2.3 \pm 0.15$ \\
$\mathbf{3 6}$ & pulegone & $42.5 \pm 2.17$ & $57.5 \pm 2.93$ & $53.3 \pm 2.72$ & $68.2 \pm 3.48$ & $68.8 \pm 3.51$ & $51.8 \pm 2.64$ \\
& Unidentified compounds & $1.5 \pm 0.13$ & $0.4 \pm 0.03$ & $4.9 \pm 0.43$ & $0.8 \pm 0.07$ & $3.4 \pm 0.29$ & $5.8 \pm 0.51$ \\
\hline
\end{tabular}

${ }^{1}$ \# indicate the compound identification number; ${ }^{2}$ Samples' names were obtained by merging the first letter of the month and the extraction time as reported in Table 1. Compounds are not listed in order of elution.

The appearance of other constituents is related to the extraction time, but some of them are always present in significant amounts. For instance, MEN (26) was present in each fraction (except $\mathrm{J} 24 \mathrm{~h}$ ) and each month. Its percentage in the July harvest was important only in the first fraction (J1h), while in the August harvest its presence is significant also in the next two fractions (up to three hours of the extraction process). September and October harvest materials were characterized by a substantial increase of MEN (up to $35.4 \%$ in O1h), particularly in the first three hours, displaying almost 10 times the amount obtained from the plant collected in July and August. The substantial presence of MEN (Figure 2b) in the CG oils has already been reported [12-14,21,22,34], sometimes up to $60 \%$ [11]. According to results of the GC/MS analysis, samples from Tarquinia clearly belong to the PUL/MEN chemotype. However, the PUL/MEN ratio is influenced by the growth stage of the plant, with the greatest increase of MEN\% during the fruiting period (October). This evolution of EO composition with the growth of the plant is somehow in good compliance with the report on EO from Corsica [11].

Crysanthenone (CRY, 17) gradually increases its amount with the extraction time. In the July harvest, its percentage was from $4.4 \%$ to $20.3 \%$ in the first three hours (J1h-J3h) up to $33.9 \%$ in the twelfth extraction hour (J12h). The same compound in the August harvest increased from $2.6 \%$ to only $9 \%$ in the first three fractions (A1h-A3h) and then rapidly increased two times between the third and sixth hours up to $29.5 \%$ in the last fraction (A24h). It can be noticed that CRY is present at higher percentage in the July harvest and August harvest, than in flowering and fruiting periods when the maximum was $18.6 \%$ and $13.4 \%$ (S24h and O24h). This chemical compound was not reported to be an important constituent of CG oils. There are only few reports about its occurrence [33] and none is even close to the percentage found in TEOCG, indicating that the Tarquinia plants belong to a PUL/MEN chemotype variant. Considering the average distillation process duration (usually up to two-three hours) in most cases, CRY un-detection is not surprising, as it becomes significant between 3 and $6 \mathrm{~h}$ of extraction. On the other hand, this compound is believed to be dependent on undergoing thermal and hydrolytic reactions during the hydro distillation process [37], possibly explaining the percentage increase with the time of extraction.

Limonene (LIM, 19) is the characteristic component of the first fraction (and exceptionally in the second) of each month (J1h, $\mathrm{A} 1 \mathrm{~h}, \mathrm{~S} 1 \mathrm{~h}$ and $\mathrm{O} 1 \mathrm{~h})$, reaching the maximum percentage $(13.6 \%)$ in the flowering material gathered in the September harvest as described in previous reports $[11,13,14,19,21,22,31-33]$. As a part of each CG chemotype, LIM could be considered as the common component, likely responsible for the plant fragrance [32]. Regarding other chemical components, some compounds are present only in particular fractions, such as methylisopulegone (27) in J24h (12.6\%). Some others are characteristic of specific months: e.g., $p$-cymene (7) is present only in the August harvest, while germacrene D (20) and $\alpha$-terpineol (38) are only found in the July harvest. Caryophyllene oxide (14) is missing only in the July harvest, while linalool (24) is not present in the EOs during reproductive periods. On the other hand, piperitenone (30) appears in the blooming period (August-September) and disappears in the October harvest, notably increased in amount in the last fractions (S6h, S12h and S24h). Piperitenone oxide (31) was detected only in the September and October 
harvest EOs, reaching the higher quantities in the fruiting period (O3h to O24h). These observations prove that some constituents are characterizing compounds in reproductive periods.

In general, the complexity of the TEOCG chemical composition was more or less the same in the first three months (from 19 to 22 compounds), and rapidly decreased in the October harvest with just 13 different chemical constituents.

In order to simulate continuous EO extraction, the 1, 2, 3, 6, 12 and $24 \mathrm{~h}$ fractions were combined to generate EOs as there would have been extracted in single runs of 2, 3, 6, 12 and $24 \mathrm{~h}$ (Supplementary Materials Tables S1-S4). The mixtures were prepared by hand and, taking into account the respective yields, reflect quite well the compositions of the original fractions, and were checked by GC/MS analyses for consistency. PUL was still the main characterizing compound, with MEN in the last two months. However, some deviations could be observed: the first mix from the October harvest (OM1, Table S4) is characterized by a very high percent of MEN (not so high in the original fractions) and quite a low percentage of PUL (in comparison with the original fractions). This occurrence could be explained by some mistake during the mixing process.

It can also be noticed that some compounds are missing in the mixtures, making them simpler than the original fractions. For instance, linalool (24), $\alpha$-terpineol (38) and cinerolone (15) in the July harvest and caryophyllene oxide (14) in the October harvest.

\subsection{Anti-Candida Activity}

The in vitro antifungal activities of TEOCGs extracted at different times and in different months, against Candida albicans (ATCC 10231), are reported in Table 6. The anti-Candida efficacy was compared to that of miconazole (minimum inhibitory concentration (MIC) $=0.016 \mathrm{mg} \cdot \mathrm{mL}^{-1}$ ), a well-known antifungal synthetic drug, and to that of solvent used to dilute the oils as blank (RPMI 1640 supplemented with Tween 80) that has no activity against Candida. The results are representative of two independent experiments ( 24 and $48 \mathrm{~h}$ of incubation) arranged in triplicate. With few exceptions, the MIC of this strain ranged from $6.24 \mathrm{mg} \cdot \mathrm{mL}^{-1}$ to $12.48 \mathrm{mg} \cdot \mathrm{mL}^{-1}$ for TEOCG extracted in the July and October harvest, and from 3.12 to $12.48 \mathrm{mg} \cdot \mathrm{mL}^{-1}$ for TEOCG extracted in the August and September harvest. Notably, some extracts showed an interesting and significant antifungal activity with MIC ranging from 0.78 to $1.56 \mathrm{mg} \cdot \mathrm{mL}^{-1}$.

Table 6. Anti-Candida albicans activities of the 44 TEOCG samples. The antibacterial tests were carried out three times, and the average values were taken as the MICs.

\begin{tabular}{|c|c|c|c|c|c|c|c|}
\hline \multirow{2}{*}{ Sample } & \multicolumn{2}{|c|}{$\mathrm{MIC} \mathrm{mg} \cdot \mathrm{mL}^{-1}$} & \multirow{2}{*}{ PUL \% } & \multirow{2}{*}{ Sample } & \multicolumn{2}{|c|}{$\mathrm{MIC} \mathrm{mg} \cdot \mathrm{mL}^{-1}$} & \multirow{2}{*}{ PUL \% } \\
\hline & $24 \mathrm{~h}$ & $48 \mathrm{~h}$ & & & $24 \mathrm{~h}$ & $48 \mathrm{~h}$ & \\
\hline $\mathrm{J} 1 \mathrm{~h}$ & 6.24 & 6.24 & 76.8 & S1h & 6.24 & 12.48 & 48.8 \\
\hline $\mathrm{J} 2 \mathrm{~h}$ & 6.24 & 12.48 & 77.7 & $\mathrm{~S} 2 \mathrm{~h}$ & 6.24 & 12.48 & 62.5 \\
\hline $\mathrm{J} 3 \mathrm{~h}$ & 0.78 & 6.24 & 64.3 & $\mathrm{~S} 3 \mathrm{~h}$ & 3.12 & 12.48 & 72.9 \\
\hline $\mathrm{J} 6 \mathrm{~h}$ & na & na & 53.2 & S6h & 1.56 & 6.24 & 74.9 \\
\hline $\mathrm{J} 12 \mathrm{~h}$ & 12.48 & 12.48 & 41.1 & S12h & 3.12 & 12.48 & 64.8 \\
\hline $\mathrm{J} 24 \mathrm{~h}$ & na & na & 37.7 & $\mathrm{~S} 24 \mathrm{~h}$ & 12.48 & na & 43.2 \\
\hline JM1 & 12.48 & 12.48 & 72.8 & SM1 & 3.12 & 12.48 & 52.4 \\
\hline JM2 & 12.48 & na & 78.6 & SM2 & 3.12 & 3.12 & 55.6 \\
\hline JM3 & 1.56 & 6.24 & 73.4 & SM3 & 1.56 & 6.24 & 60.8 \\
\hline JM4 & 6.24 & 6.24 & 77.6 & SM4 & 0.78 & 6.24 & 53.6 \\
\hline JM5 & 12.48 & 12.48 & 76.2 & SM5 & 3.12 & 6.24 & 55.6 \\
\hline A1h & 3.12 & 12.48 & 80.8 & O1h & 6.24 & 12.48 & 42.5 \\
\hline $\mathrm{A} 2 \mathrm{~h}$ & 3.12 & 6.24 & 84.7 & $\mathrm{O} 2 \mathrm{~h}$ & 6.24 & 12.48 & 57.5 \\
\hline A3h & 1.56 & 3.12 & 80.0 & O3h & 6.24 & 12.48 & 53.3 \\
\hline A6h & 3.12 & 6.24 & 66.0 & O6h & 12.48 & 12.48 & 68.2 \\
\hline $\mathrm{A} 12 \mathrm{~h}$ & 6.24 & na & 55.4 & $\mathrm{O} 12 \mathrm{~h}$ & 12.48 & 12.48 & 68.8 \\
\hline A24h & 6.24 & 12.48 & 49.9 & O24h & na & na & 51.8 \\
\hline AM1 & 3.12 & 6.24 & 75.7 & OM1 & 6.24 & 12.48 & 10.1 \\
\hline AM2 & 0.78 & 3.12 & 78.8 & OM2 & 6.24 & 12.48 & 50.5 \\
\hline AM3 & 3.12 & 6.24 & 76.9 & OM3 & 12.48 & 12.48 & 52.0 \\
\hline AM4 & 3.12 & 3.12 & 76.4 & OM4 & 12.48 & 12.48 & 49.8 \\
\hline AM5 & 12.48 & 12.48 & 79.4 & OM5 & 6.24 & 12.48 & 52.1 \\
\hline
\end{tabular}


Usually, the third fraction (between the second and third hours of extraction) showed good activity (J3h, A3h) or even the fourth one (between the third and sixth hours) in the case of the September harvest (S6h). In the case of mixtures, significant activity was detected for the third or fourth mix (JM3, AM3, SM3 and SM4). On the contrary, the October harvest was lacking any significant activity.

A survey of the available literature highlighted that most of the data about antimicrobial activity are related to $\mathrm{CN}[21,26,38]$, but not to the subspecies investigated in this paper. To the best of our knowledge, the only data reported for CG was from the Montenegrin material [22] and from Turkey [23,39]. The EO was screened against the following bacteria: Escherichia coli, Staphylococcus aureus, Salmonella enteritidis, Bacillus subtilis, Pseudomonas aeruginosa and fungi Aspergillus niger. All the microorganisms (except $S$. enteritidis) were found to be susceptible, specifically A. niger [22]. Antimicrobial activity of the Turkish sample was evaluated, using the disc diffusion method, and the study showed that all the bacteria (particularly B. subtilis, Staphylococcus epidermidis, Stenotrophomonas maltophilia) and C. albicans were affected by the EO. In the study, the occurrence was explained by the high percentage of PUL [23]. In addition, different CG extracts and fractions were investigated against Gram(+) B. subtilis and Gram(-) E. coli and Salmonella typhimurium [39]. The analysis showed better activity of the water extract than the methanol one, whereas the fractions prepared had greater bactericidal efficacy, especially the dichloromethane one. However, methanolic extract and the ethyl acetate fraction failed to inhibit all tested bacteria.

The contribution of some pure constituents to the EO effectiveness has also been evaluated [21]. The main constituents of TEOCG were analyzed, and the only one endowed with antibacterial effectiveness was PUL. The authors indicated that the effectiveness of the essence was almost exclusively due to that constituent [21]. The results indicate that PUL is likely not the only chemical component responsible for the antifungal activities, although it is always the dominant one, on the other hand, this is just an observation as advanced chemometric and statistical analyses need to be carried out. Looking at Tables S1-S4, it is evident that other minor constituents are capable of microbiological activity as well and might be involved in the inhibition process with some synergistic mechanism resembling the one recently described [8]. This is in compliance with the phytocomplex hypothesis discussed elsewhere [40,41]. Further analysis of data indicates the lack of any significant correlation between the antimicrobial activity and the vegetative stage of the plant (Table 6). However, this is in contrast with some literature data which indicate the highest antimicrobial efficacy of EOs obtained during the blooming period of a plant [42-44].

\section{Materials and Methods}

\subsection{Plant Material}

Aerial parts of CG were collected in a wild area about $15 \mathrm{~km}$ from the city of Tarquinia (Viterbo, Italy), during 2015. Material was collected in summer and early autumn periods of the year and monitored for 4 months, from July to October thus covering before-, within- and post-flowering periods. Taxonomic identifications of the species were conducted according to the official European flora [9] and the national Italian one [45].

\subsection{EO Extraction}

Similarly, as previously reported [8] fresh plant material $(2.5 \mathrm{~kg})$ was subjected to steam distillation separating EOs at an interval time of 1, 2, 3, 6, 12 and $24 \mathrm{~h}$ and worked out to furnish six fractions of yellow paled EOs. In addition, EOs mixtures were prepared by mixing each fraction as follows: M1 $(1+2 \mathrm{~h}$ of extraction), M2 $(1+2+3 \mathrm{~h}), \mathrm{M} 3(1+2+3+6 \mathrm{~h}), \mathrm{M} 4(1+2+3+6+12 \mathrm{~h})$ and M5 $(1+2+3+6+12+24 \mathrm{~h})$. The mixtures were prepared by adding different amounts of diethyl ether to each EO fraction up to $10 \mathrm{~mL}$ in total (e.g., $7 \mathrm{~mL}$ of diethyl ether to $3 \mathrm{~mL}$ of the EO). Desired oily mixes were obtained by combining $1 \mathrm{~mL}$ of each ether-EO solution and then leaving ether to evaporate. 
This procedure allowed the study of EO extraction by obtaining its fractions after 2, 3, 6, 12 and $24 \mathrm{~h}$, within parallel procedures which were not interrupted.

\subsection{EO Analysis}

The gas chromatographic/mass spectrometric (GC/MS analysis was carried out with a GC-MS and flame ionization detector (FID) as previously reported [8]. The analyses were carried out twice showing reproducible results.

\subsection{Antimicrobial Assay}

As previously reported, the MIC was determined by the micro-broth dilution method (microsterile plate) according to the Clinical and Laboratory Standards Institute/National Committee for Clinical Laboratory Standards (CLSI/NCCLS) Approved Standard M27-A3, 2008 [NCCLS]. Miconazole $\left(0.5 \mathrm{mg} \cdot \mathrm{mL}^{-1}\right)$, used as positive control, was prepared by dissolving the agent in endotoxin free water. EO solutions $\left(100 \mathrm{mg} \cdot \mathrm{mL}^{-1}\right)$ were prepared in RPMI 1640. Shortly, to determine the MIC of TEOCG extracted at different times and in different months, or miconazole, RPMI-1640 supplemented with 3-(N-morpholino)propanesulfonic acid (MOPS) at pH 7 was used. TEOCG was diluted in RPMI-1640 supplemented with Tween 80 (final concentration of $0.001 \% v / v$ ). RPMI-1640 supplemented with Tween 80 was used as blank. Dilutions, 11 increasing concentrations, ranging from 0.012 to $12.48 \mathrm{mg} \cdot \mathrm{mL}^{-1}$ of the $\mathrm{EO}$, were prepared in 96-well plates. The inoculum size was about $2.5 \times 10^{3}$ cells $\cdot \mathrm{mL}^{-1}$. The plates were incubated at $30{ }^{\circ} \mathrm{C}$ for $24-48 \mathrm{~h}$.

\subsection{Statistical Evaluations}

Relative standard deviations and statistical significance (Student's $t$ test; $p \leq 0.05$ ) were given where appropriate for all data collected. One-way ANOVA and Least Significant Difference (LSD) post hoc Tukey's honest significant difference test were used for comparing the bioactive effects of different samples. All computations were made using the statistical software STATISTICA 6.0 (StatSoft Italia s.r.l., Padova, Italy).

\section{Conclusions}

Since the very beginning, plants have provided human beings with a source of inspiration for novel medicines. Considering the increased interest in natural substances, the deepening of the knowledge of the potential of different aromatic plants can lead to important results in the discovery of both sustainable and effective drug treatment. In line with our previous studies on MS [8], a 24-h extraction procedure was applied to CG in terms of a different harvesting period (four months) and extraction duration. In this study, we investigated the chemical composition of 44 TEOCG samples, showing that the PUL/MEN chemotype was represented in Tarquinia, but the ratio varied greatly according to the growth phase of the plant. The MEN percentage increased at the blooming period, while the PUL decreased. The CRY amount increased with the longer distillation process. This could be considered as the characteristic of TEOCG or the result of transformation during the process. Antifungal activities of the samples have also been investigated, showing the significant efficacy of some samples. Taken together, obtained results point to synergistic effects of all the constituents of the EO, and that PUL cannot be considered as the only responsible constituent. It can be speculated that some components could have a positive and additive biological role, as well as possible anti-synergism with the most dominant $\mathrm{EO}$ ingredients.

In relation to the biological activity, the period of extraction seems to be of importance since great activities were shown by EOs collected between the third and sixth hours. Although the harvesting period seems not to be important, EO from the fruiting stage showed the lowest anti-Candida activity. Consideration should also be given to the EO production yield or the chemical composition, and harvesting in August led to the highest EO production, as well as PUL percentage. On the other hand, the main part of EOs was extracted in the first three (July harvest/August harvest) or 
six hours (September harvest/October harvest). Based on the extraction time in the July and August harvests, PUL percentage reached the maximum during the first three hours (J2h, A2h) whereas it diminished during the last three extraction phases. In the reproductive period of September and October, the situation was different and the PUL percentage maximum was between the third and sixth (S6h) or twelfth hours (O12h).

Further investigation of other biological activities will be carried out in due course.

Supplementary Materials: The following are available online at: http:/ www.mdpi.com/1420-3049/22/2/203/ s1, Table S1: Chemical composition (\%) of TEOCG mixtures from July; Table S2: Chemical composition (\%) of TEOCG mixtures from August; Table S3: Chemical composition (\%) of TEOCG mixtures from September; Table S4: Chemical composition (\%) of TEOCG mixtures from October.

Acknowledgments: The authors are thankful to Branka Knežević for proofreading the paper. This research has been funded with support from the European Commission. This publication reflects the views only of the authors, and the Commission cannot be held responsible for any use which may be made of the information contained therein. The research has also been funded by University of Ferrara Research grant (FAR 2015) and Ambrosialab s.r.l., Ferrara, Italy

Author Contributions: R.R. conceived the works, designed the experiments and organized the written manuscript; M.B. and S.G. performed most of the extraction and harvesting experiments and parts of the data analysis; S.G. and F.P. performed the GC/MS experiments and part of data analysis. M.S. contributed reagents/materials/analysis tools; A.B., E.A. C.R. and S.M. performed the microbiology experiments. A.M. contributed to write and revise the paper. All the authors contributed to write the paper.

Conflicts of Interest: The authors declare no conflict of interest. The founding sponsors had no role in the design of the study, in the collection, analyses, or interpretation of data, in the writing of the manuscript, and in the decision to publish the results.

\section{References}

1. Masango, P. Cleaner production of essential oils by steam distillation. J. Clean. Prod. 2005, 13, 833-839. [CrossRef]

2. Tongnuanchan, P.; Benjakul, S. Essential oils: Extraction, bioactivities, and their uses for food preservation. J. Food Sci. 2014, 79, R1231-R1249. [CrossRef] [PubMed]

3. Bakkali, F.; Averbeck, S.; Averbeck, D.; Idaomar, M. Biological effects of essential oils-A review. Food Chem. Toxicol. 2008, 46, 446-475. [CrossRef] [PubMed]

4. Kalemba, D.; Kunicka, A. Antibacterial and antifungal properties of essential oils. Curr. Med. Chem. 2003, 10, 813-829. [CrossRef] [PubMed]

5. Reichling, J.; Schnitzler, P.; Suschke, U.; Saller, R. Essential oils of aromatic plants with antibacterial, antifungal, antiviral, and cytotoxic properties-An overview. Forsch. Komplementmed. 2009, 16, 79-90. [CrossRef] [PubMed]

6. Pietrella, D.; Angiolella, L.; Vavala, E.; Rachini, A.; Mondello, F.; Ragno, R.; Bistoni, F.; Vecchiarelli, A. Beneficial effect of Mentha suaveolens essential oil in the treatment of vaginal candidiasis assessed by real-time monitoring of infection. BMC Complement. Altern. Med. 2011, 11, 18. [CrossRef] [PubMed]

7. Naveed, R.; Hussain, I.; Mahmood, M.S.; Akhtar, M. In vitro and in vivo evaluation of antimicrobial activities of essential oils extracted from some indigenous spices. Pak. Vet. J. 2013, 33, 413-417.

8. Garzoli, S.; Pirolli, A.; Vavala, E.; Di Sotto, A.; Sartorelli, G.; Božović, M.; Angiolella, L.; Mazzanti, G.; Pepi, F.; Ragno, R. Multidisciplinary approach to determine the optimal time and period for extracting the essential oil from Mentha suaveolens Ehrh. Molecules 2015, 20, 9640-9655. [CrossRef] [PubMed]

9. Ball, P.W.; Getliffe, F. Calamintha Miller. In Flora Europaea; Tutin, T., Heywood, V., Burges, N., Moore, D., Valentine, D., Walters, S., Webb, D., Eds.; Cambridge University Press: Cambridge, UK, 1968; Volume 3, pp. 166-167.

10. Pacifico, S.; Galasso, S.; Piccolella, S.; Kretschmer, N.; Pan, S.; Marciano, S.; Bauer, R.; Monaco, P. Seasonal variation in phenolic composition and antioxidant and anti-inflammatory activities of Calamintha nepeta (L.) Savi. Food Res. Int. 2015, 69, 121-132. [CrossRef]

11. Ristorcelli, D.; Tomi, F.; Casanova, J. Essential Oils of Calamintha nepeta subsp. nepeta and subsp. glandulosa from Corsica (France). J. Essent. Oil Res. 1996, 8, 363-366. [CrossRef] 
12. Şarer, E.; Solakel Pançalı, S. Composition of the essential oil from Calamintha nepeta (L.) Savi ssp. glandulosa (Req.) P. W. Ball. Flavour Fragr. J. 1998, 13, 31-32.

13. Alan, S.; Kürkçüoglu, M.; Hüsnü, K.; Başer, K. Composition of essential oils of Calamintha nepeta (L.) Savi subsp. nepeta and Calamintha nepeta (L.) Savi subsp. glandulosa (Req.) P.W. Ball. Asian J. Chem. 2011, 23, 2357-2360.

14. Demirci, B.; Temel, H.; Portakal, T.; Kırmızıbekmez, H.; Demirci, F.; Başer, K. Inhibitory effect of Calamintha nepeta subsp. glandulosa essential oil on lipoxygenase. Turk. J. Biochem. 2011, 36, $290-295$.

15. Marongiu, B.; Piras, A.; Porcedda, S.; Falconieri, D.; Maxia, A.; Gonçalves, M.; Cavaleiro, C.; Salgueiro, L. Chemical composition and biological assays of essential oils of Calamintha nepeta (L.) Savi subsp. nepeta (Lamiaceae). Nat. Prod. Res. 2010, 24, 1734-1742. [CrossRef] [PubMed]

16. Negro, C.; Notarnicola, S.; De Bellis, L.; Miceli, A. Intraspecific variability of the essential oil of Calamintha nepeta subsp. nepeta from Southern Italy (Apulia). Nat. Prod. Res. 2013, 27, 331-339. [CrossRef] [PubMed]

17. Souleles, C.; Argyriadou, N.; Philianos, S. Constituents of the essential oil of Calamintha nepeta. J. Nat. Prod. 1987, 50, 510-511. [CrossRef]

18. De Pooter, H.; Goetghebeur, P.; Schamp, N. Variability in composition of the essential oil of Calamintha nepeta. Phytochemistry 1987, 26, 3355-3356. [CrossRef]

19. Ćavar, S.; Vidić, D.; Maksimović, M. Volatile constituents, phenolic compounds, and antioxidant activity of Calamintha glandulosa (Req.) Bentham. J. Sci. Food Agric. 2012, 93, 1758-1764. [CrossRef] [PubMed]

20. Conforti, F.; Marrelli, M.; Statti, G.; Menichini, F.; Uzunov, D.; Solimene, U.; Menichini, F. Comparative chemical composition and antioxidant activity of Calamintha nepeta (L.) Savi subsp. glandulosa (Req.) Nyman and Calamintha grandiflora (L.) Moench (Labiatae). Nat. Prod. Res. 2012, 26, 91-97. [CrossRef] [PubMed]

21. Flamini, G.; Cioni, P.; Puleio, R.; Morelli, I.; Panizzi, L. Antimicrobial activity of the essential oil of Calamintha nepeta and its constituent pulegone against bacteria and fungi. Phytother. Res. 1999, 13, 349-351. [CrossRef]

22. Kitić, D.; Jovanović, T.; Ristić, M.; Palić, R.; Stojanović, G. Chemical composition and antimicrobial activity of the essential oil of Calamintha nepeta (L.) Savi ssp. glandulosa (Req.) P.W. Ball from Montenegro. J. Essent. Oil Res. 2002, 14, 150-152.

23. Sarac, N.; Ugur, A. The In Vitro antimicrobial activities of the essential oils of some Lamiaceae species from Turkey. J. Med. Food 2009, 12, 902-907. [CrossRef] [PubMed]

24. Ceker, S.; Agar, G.; Alpsoy, L.; Nardemir, G.; Kizil, H. Protective role of essential oils of Calamintha nepeta L. on oxidative and genotoxic demage caused by Alfatoxin B1 in vitro. Fresenius Environ. Bull. 2013, 22, 3258-3263.

25. Adams, M.; Berset, C.; Kessler, M.; Hamburger, M. Medicinal herbs for the treatment of rheumatic disorders-A survey of European herbals from the 16th and 17th century. J. Ethnopharmacol. 2009, 121, 343-359. [CrossRef] [PubMed]

26. Panizzi, L.; Flamini, G.; Cioni, P.; Morelli, I. Composition and antimicrobial properties of essential oils of four Mediterranean Lamiaceae. J. Ethnopharmacol. 1993, 39, 167-170. [CrossRef]

27. Stanić, G.; Blažević, N.; Brkić, D.; Lukač, G. The composition of essential oils of Calamintha nepeta (L.) Savi subsp. glandulosa (Req.) P. W. Ball and Calamintha sylvatica Bromf. subsp. sylvatica. Acta. Pharm. 1999, 49, 107-112.

28. Akgül, A.; De Pooter, H.; De Buyck, L. The Essential oils of Calamintha nepeta subsp. glandulosa and Ziziphora clinopodioides from Turkey. J. Essent. Oil Res. 1991, 3, 7-10.

29. Couladis, M.; Tzakou, O. Essential oil of Calamintha nepeta subsp. glandulosa from Greece. J. Essent. Oil Res. 2001, 13, 11-12. [CrossRef]

30. Kokkalou, E.; Stefanou, E. The volatile oil of Calamintha nepeta (L.) savi subsp. glandulosa (req.) P. W. Ball, endemic to Greece. Flavour Fragr. J. 1990, 5, 23-26. [CrossRef]

31. Kirimer, N.; Baser, K.; Özek, T.; Kürkçüoglu, M. Composition of the essential oil of Calamintha nepeta subsp. glandulosa. J. Essent. Oil Res. 1992, 4, 189-190. [CrossRef]

32. De Pooter, H.; De Buyck, L.; Schamp, N. The volatiles of Calamintha nepeta subsp. glandulosa. Phytochemistry 1986, 25, 691-694. [CrossRef] 
33. Riela, S.; Bruno, M.; Formisano, C.; Rigano, D.; Rosselli, S.; Saladino, M.; Senatore, F. Effects of solvent-free microwave extraction on the chemical composition of essential oil of Calamintha nepeta (L.) Savi compared with the conventional production method. J. Sep. Sci. 2008, 31, 1110-1117. [CrossRef] [PubMed]

34. Pagni, A.; Catalano, S.; Cioni, P.; Coppi, C.; Morelli, I. Etudes morpho-anatomiques et phytochimiques de Calamintha nepeta (L.) Savi (Labiétes). Plant. Med. Phytothér. 1990, 24, $203-213$.

35. Baser, K.; Kirimer, N.; Tümen, G. Pulegone-rich essential oils of Turkey. J. Essent. Oil Res. 1998, 10, 1-8. [CrossRef]

36. José Pérez-Alonso, M.; Velasco-Negueruela, A.; López Sáez, J. The volatiles of two Calamintha species growing in Spain, C. sylvatica Bromf. and C. nepeta (L.) Savi. Acta Hortic. 1993, 333, 255-260. [CrossRef]

37. Asfaw, N.; Storesund, H.; Skattebøl, L.; Aasen, A. Coexistence of chrysanthenone, filifolone and (Z)-isogeranic acid in hydrodistillates. Artefacts! Phytochemistry 2001, 58, 489-492. [CrossRef]

38. Gormez, A.; Bozari, S.; Yanmis, D.; Gulluce, M.; Sahin, F.; Agar, G. Chemical composition and antibacterial activity of essential oils of two species of Lamiaceae against phytopathogenic bacteria. Pol. J. Microbio. 2015, 64, 121-127.

39. Foto, E.; Zilifdar, F.; Yeșilyurt, E.; Biypi, B.; Diril, N. The in vitro antibacterial activity of some extracts and fractions of Calamintha nepeta (L.) Savi subsp. glandulosa (Req.) P.W. Ball (Lamiaceae). In Proceedings of the 11th International Symposium of Pharmaceutical Sciences, Ankara, Turkey, 9-12 June 2015; Ankara University Faculty of Pharmacy Publication, Book of Abstracts. ; pp. 397-398.

40. Neto, A.; Netto, J.; Pereira, P.; Pereira, A.; Taleb-Contini, S.; França, S.; Marques, M.O.; Beleboni, R.O. The role of polar phytocomplexes on anticonvulsant effects of leaf extracts of Lippia alba (Mill.) N.E. Brown chemotypes. J. Pharm. Pharmacol. 2009, 61, 933-939. [CrossRef] [PubMed]

41. Maietti, S.; Rossi, D.; Guerrini, A.; Useli, C.; Romagnoli, C.; Poli, F.; Bruni, R.; Sacchetti, G. A multivariate analysis approach to the study of chemical and functional properties of chemo-diverse plant derivatives: Lavender essential oils. Flavour Fragr. J. 2013, 28, 144-154. [CrossRef]

42. Burt, S. Essential oils: Their antibacterial properties and potential applications in foods-A review. Int. J. Food Microbiol. 2004, 94, 223-253. [CrossRef] [PubMed]

43. Chorianopoulos, N.; Evergetis, E.; Mallouchos, A.; Kalpoutzakis, E.; Nychas, G.; Haroutounian, S. Characterization of the essential oil volatiles of Satureja thymbra and Satureja parnassica: Influence of harvesting time and antimicrobial activity. J. Agric. Food Chem. 2006, 54, 3139-3145. [CrossRef] [PubMed]

44. Chorianopoulos, N.; Kalpoutzakis, E.; Aligiannis, N.; Mitaku, S.; Nychas, G.; Haroutounian, S. Essential oils of Satureja, Origanum, and Thymus species: Chemical composition and antibacterial activities against foodborne pathogens. J. Agric. Food Chem. 2004, 52, 8261-8267. [CrossRef] [PubMed]

45. Pignatti, S. Flora d'Italia; Edagricole: Bologna, Italy, 1982; pp. 1-732.

Sample Availability: Samples of the compounds are available from the authors.

(C) 2017 by the authors; licensee MDPI, Basel, Switzerland. This article is an open access article distributed under the terms and conditions of the Creative Commons Attribution (CC BY) license (http:/ / creativecommons.org/licenses/by/4.0/). 